\title{
Pelatihan Social Entrepreneurship Bagi Masyarakat Pinggiran di Kota Surabaya Barat
}

\author{
Choirul Mahfud ${ }^{1)}$, Arman Hakim Nasution ${ }^{2)}$, Dyah Satya Yoga Agustin ${ }^{3)}$, \\ Ratna Rintaningrum ${ }^{4)}$, Niken Prasetyawati ${ }^{5)}$ \\ 1,2,3,4,5) Institut Teknologi Sepuluh Nopember (ITS) Surabaya \\ choirul.mahfud@its.ac.id
}

\begin{abstract}
ABSTRAK: Pelatihan social entrepeneurship merupakan salah satu cara untuk menjawab masalah sosial ekonomi masyarakat pinggiran di kota. Sasaran utama dari kegiatan ini adalah para pemuda dari karang taruna di daerah Tandes, Surabaya Barat. Strategi dan metode yang dipraktikkan dalam pelatihan ini adalah pemberian materi dengan ceramah, diskusi dan melihat video inspirasi dari Youtube. Pelatihan ini bertujuan untuk meningkatkan wawasan dan ketrampilan berpikir para pemuda agar lebih berdaya secara sosial. Lebih dari itu, harapannya dengan memberikan wawasan mengenai social entrepeneurship dapat menjadi modal awal untuk menjadi mewujudkan kemandirian dari masyarakat khususnya di daerah pinggiran kota melalui usaha melakukan perubahan berbasis sosial ekonomi.
\end{abstract}

Kata kunci : Social Entrepreneurship, Pemberdayaan, dan Masyarakat Pinggiran.

ABSTRACT: Social Entrepreneurship training is one way to address the socio-economic problems of suburban communities in cities. The main target of this activity is young people from Karang taruna in the Tandes area, West Surabaya. The strategies and methods practiced in this training are the provision of material with lectures, discussions and viewing inspirational videos from Youtube. This training aims to increase the insight and thinking skills of young people to be more socially empowered. More than that, by this providing insights on social entrepreneurship can be an initial capital to be able to realize the independence of the community, especially in suburban areas through efforts to make changes based on social economy.

Keywords: Social Entrepreneurship, Empowerment, and Periphery Communities

\section{PENDAHULUAN}

Ada problem kesenjangan antara kenyataan dan ideal yang terjadi di masyarakat pinggiran kota di Surabaya bagian barat. Ada sebagian masyarakat yang sangat kaya yang tinggal di perumahan elit, namun di sisi lain ada yang tinggal di rumah biasa yang dekat dengan ekonomi berpenghasilan rendah. Rumahnya pun tentu saja tidak jelas status hak miliknya. Oleh karena itu, pelatihan socio entrepreneurship dimaksudkan untuk membuka pintu kesadaran dalam diri masyarakat untuk memahami masalah yang dihadapi dan bagaimana bisa mencari solusi terbaik untuk membangun kemandirian dan kesejahteraan ekonomi.

Pelatihan socio entrepreneurship memiliki pengaruh positif bagi siapa saja dan dimana saja yang ingin mengembangkan kemampuannya dalam aspek sosial ekonomi yang lebih baik (Nasution, 20017). Pelatihan socio entrepreneurship pada umumnya 
menggabungkan aspek kompetensi bisnis, social skills, kreativitas, inovasi dan spirit untuk maju (Nasution, 2001).

Berdasarkan pengamatan yang dilakukan oleh tim dosen Insitut Teknologi Sepuluh Nopember (ITS) Surabaya selama ini, realitas masyarakat pinggiran di kota Surabaya bagian barat masih dalam posisi yang sulit untuk memecahkan masalahnya sendiri dalam aspek sosial ekonomi. Padahal, kemandirian dan kemampuan dalam memecahkan masalah itu merupakan bagian penting dari karakter masyarakat kota yang maju dan sejahtera. Dari latar belakang inilah, tim dosen Institut Teknologi Sepuluh Nopember mengadakan program pelatihan socio entrepreneurship bagi masyarakat pinggiran sebagai bagian dari tanggungjawab kampus ITS kepada masyarakat.

\section{PERMASALAHAN}

Berdasarkan analisis situasi dan kondisi yang dilakukan, ada beberapa permasalahan yang melatarbelakangi kegiatan dan program dilakukan program pengabdian masyarakat yang berupa Pelatihan Social Entrepreneurship Bagi Masyarakat Pinggiran di Kota Surabaya Barat ini dilakukan, yaitu:

1. Para Pemuda Karangtaruna di Kecamatan Tandes Surabaya hanya melakukan kegiatan rutin olahraga agustusan yang bersifat non-produktif. Sedangkan untuk menuju kelompok yang produktif secara perekonomian, para pemuda juga diharapkan memiliki semangat kemandirian, inovatif dan kreatif, sehingga mampu meningkatkan perekonomian keluarga dan masyarakat.

2. Terbatasnya kompetensi dan keterampilan yang dimiliki oleh para pemuda karang taruna yang menunjang perekonomian masyarakat.

3. Minimnya pengetahuan tentang social entrepreneurship

\section{METODE PELAKSANAAN}

Kegiatan Pelatihan Social Entrepreneurship Bagi Masyarakat Pinggiran di Kota Surabaya Barat secara umum dilaksanakan dengan metode ceramah, diskusi dan melihat video inspirasi tentang social entrepereneurship. Materi yang disajikan diberikan contohnya melalui gambar yang menarik. Setelah materi disampaikan oleh tim pemateri, maka dibentuk kelompok para pemuda yang seolah diajak bekerjasama dengan kelompok lainnya dalam pelatihan tersebut. Harapannya bahwa kelompok ini dapat mengakomodir dan saling bekerjasama melalui kegiatan yang bekerlanjutan. Kegiatan yang terstruktur ini tentu saja disesuaikan dengan program kerja yang dibuat oleh lembaga atau organisasi karang taruna di daerah tersebut, sehingga ada saling pengertian dan saling mendukung.

\section{PELAKSANAAN}

Secara umum, pelaksanaan kegiatan pada pengabdian masyarakat yang berupa pelatihan Social Entrepreneurship Bagi Masyarakat Pinggiran di Kota Surabaya Barat 
tergolong kegiatan sukses dan bermanfaat bagi masyarakat pinggiran khususnya para pemuda pemudi Karang taruna di Tandes, Surabaya Barat. Tujuan dalam kegiatan pelatihan Social Entrepreneurship bagi masyarakat pinggiran di Kota Surabaya Barat ini adalah meningkatkan wawasan, pemahaman, dan ketrampilan berpikir para peserta yaitu para pemuda karang taruna calon pemimpin keluarga dan masyarakat. Khususnya dalam menghadapi tantangan masyarakat saat ini dengan solusi melalui kegiatan social entrepreneurship. Target yang diinginkan yaitu terbentuknya kelompok social entrepreneur dari kaum muda yang memiliki kegiatan berkelanjutan berupa kegiatan social entrepreneurship.

\section{HASIL DAN PEMBAHASAN}

Kegiatan pelatihan Social Entrepreneurship Bagi Masyarakat Pinggiran di Kota Surabaya Barat ini benar-benar memberikan manfaat dan inspirasi bagi peserta yang terlibat. Hal ini bisa dipahami dari proses peserta yang mengikuti materi yang disampaikan. Tidak hanya itu, peserta yang meliputi para pemuda dari karang taruna di kawasan Tandes Surabaya Barat tersebut juga antusias dalam berdiskusi secara berkelompok. Secara langsung atau tidak, partisipasi aktif dirasakan. Kemerdekaan belajar bersama menjadi pengalaman tambahan selama mengikuti kegiatan program pelatihan ini. Kemampuan pemateri dalam menyampaikan pesan tentang perlunya belajar dengan menunjukkan contoh dalam video inspirasi mengenai social entrepreneurship menjadikan peserta lebih bergairah untuk mencoba menjadi social entrepreneur. Pemateri juga meyakinkan peserta bahwa social entrepreneurship bisa turut membangun jiwa kreatif sekaligus ekonomi kreatif masyarakat pinggiran kaum muda masyarakat di kawasan barat Surabaya. Secara umur, peserta dari tim karang taruna terdiri dari kelompok umur antara 17-22 yang mana semua merupakan generasi bangsa yang bisa merasakan dampak dan manfaat positif dari kegiatan pelatihan tersebut. Secara umum, materi yang paling diminati oleh peserta berkaitan dengan membangun bisnis ekonomi kreatif berbasis media sosial. Artinya peserta bisa bekerja melalui handpone nya. Selebihnya juga hal terkait dengan pendidikan untuk anak usia dini. Hal ini terutama dari pemudi atau perempuan yang juga menarik kepedulian pada generasi anak usia dini. Titik tekan dalam pelatihan menjadi menarik karena di satu sisi berbisnis, dan di sisi lain juga berjiwa sosial. Artinya menjadi orang sukses sekaligus peduli kepada masyarakat adalah impian dari generasi ke generasi yang perlu dilanjutkan oleh peserta yang terlibat dalam pelatihan. Dari sinilah, program pelatihan ini diharapkan bisa terus dilanjutkan dan bermanfaat untuk mendukung keseimbangan kehidupan sosial ekonomi masyarakat pinggiran di kawasan barat Kota Surabaya.

\section{KESIMPULAN DAN SARAN}

Mengacu pada hasil pelaksanaan dari pengabdian berupa pelatihan Social Entrepreneurship bagi masyarakat pinggiran di Kota Surabaya Barat ini dapat diambil 
sebuah kesimpulan bahwa kegiatan pelatihan ini dapat menambah pengetahuan, wawasan dan cakrawala serta ketrampilan masyarakat pinggiran khususnya yang mengikuti pelatihan tentang bagaimana cara meningkatkan produktivitas dan kreativitas untuk menjadi social entrepreneur.

Agar kegiatan social entrepreneurship bisa terus bermanfaat secara berkesinambungan, maka diperlukan monitoring sekaligus mentoring lanjutan melalui grup Whatsapp dan media sosial lainnya. Dengan adanya program lanjut, tentu saja menjadi lebih terarah dan jelas hasil dari pelatihan yang memberdayakan para pemuda di Kecamatan Tandes kota Surabaya. Lebih dari itu, bisa saling berbagi pengalaman dan ilmu serta ketrampilan dari semua terkait bagaimana cara menghadapi masalah dari usaha yang dilakukan.

\section{DAFTAR PUSTAKA}

Hidayat, MC, Mahfud, Choirul, 2019, Potential Development Management of Students in Islam, Ta'dib: Journal of Islamic Education (Jurnal Pendidikan Islam) Volume 24, 2, 293-302.

Mahfud., C. 2018, Chinese Muslim Community Development in Contemporary Indonesia: Experiences of PITI in East Java, Studia Islamika, 25 (3), 471502

Mahfud., C. 2019, Imagined Islamic Societies and the Role of Ulema in Contemporary Indonesia, AKADEMIKA: Jurnal Pemikiran Islam, 24 (2), 269-278

Mahfud, Choirul, 2019, A Policy Analysis of Islamic Education Budget in Indonesia, Edukasia Islamika 4 (1), 1-17

Nasution, AH, Arifin, B, Suef, M, 2007, Entrepreneurship: membangun spirit teknopreneurship, Yogyakarta: Penerbit Andi.

Nasution., A.H. 2001, Membangun Spirit Entrepreneur Muda Indonesia: Suatu Pendekatan Praktis dan Analitis, Jakarta: PT Elex Media Komputindo. 